\title{
Newer report of Rugose Spiraling Whitefly, Aleurodicus rugioperculatus Martin (Hemiptera: Aleyrodidae) in India
}

\author{
K. S. Karthick*, C. Chinniah, P. Parthiban, A. Ravikumar \\ Department of Agricultural Entomology, Agricultural College and Research Institute, Tamil Nadu Agricultural \\ University, Madurai - 625 104, Tamil Nadu, India. \\ *Corresponding Author: K. S. Karthick, Department of Agricultural Entomology, Agricultural College \\ and Research Institute, Tamil Nadu Agricultural University, Madurai - 625 104, Tamil Nadu, India.
}

\begin{abstract}
The rugose spiraling whitefly (RSW), Aleurodicus rugioperculatus was first described by Martin from Belize in Central America in 2004 based on puparium collected from the leaves of coconut. This whitefly was first documented as a pest in Florida in urban landscapes in Miami Dade County in March 2009, but little is known about its biology. The RSW is highly polyphagous with more than 118 hosts belonging to 43 plant families, including several economically important crops in the United States. Division of Plant Industry host record frequency data from 2009 to 2012 proved that $22 \%$ of RSW affected palm species, $16 \%$ gumbo limbo, $10 \%$ on Callophyllum spp., $9 \%$ avocado, $3 \%$ mango and within the Areacaceae (palms), 44\% coconut. Initially, this whitefly was observed in several coconut farms in the Pollachi area of Coimbatore district, Tamil Nadu and Palakkad from kerala during July - August 2016. A total of 17 plant species under 11 families were recorded as preferred hosts of A. rugioperculatus. The infestation was found very severe on lower leaves compared to that of the middle and upper young leaves in dwarf and hybrid coconut palms which are about 4 to 6 years old. The population of nymphs ranged between 18 to 37 nymphs $/ \mathrm{cm}^{2}$ of leaflet. Natural enemies to recorded were RSW viz., Encarsia guadeloupae Viggiani, E. noyesi, Alueroctonus vittatus, Nephaspis oculata. Among these E. guadeloupae potential biocontrol agent against RSW as 50 to $60 \%$ natural parasitization.
\end{abstract}

Keywords: Aleurodicus rugioperculatus, Gumbo limbo, Nephaspis oculata, Encarsia guadeloupae

\section{INTRODUCTION}

Whiteflies are very important pests of numerous agricultural crops. Whiteflies belong to the order Hemiptera and comprise a single superfamily, Aleyrodoidea, within the suborder Sternorrhyncha. They are all placed in a single family, Aleyrodidae, and are small sap-sucking, usually inconspicuous insects. They cause the highest economic damage on vegetable and ornamental plant species. Currently, there are 442 species of whiteflies belonging to 63 genera known from India. Recently, rugose spiraling whitefly (RSW), Aleurodicus rugioperculatus Martin (Hemiptera: Aleyrodidae), was observed on coconut palm (Cocos nucifera L). The etymology of rugose (i.e. fluted / irregularly corrugate) appearance of the puparial operculum. The origin of RSW was first described from Belize in Central America in 2004 (Martin, 2004). It was first documented as a pest in Florida in urban landscapes in Miami Dade County in March 2009. The RSW is highly polyphagous with more than 118 hosts belonging to 43 plant families, including several economically important crops in the United States (Francis et al., 2016). Division of Plant Industry host record frequency data from 2009 to 2012 proved that $22 \%$ of RSW affected palm species, $16 \%$ gumbo limbo, $10 \%$ on Callophyllum spp., $9 \%$ avocado, $3 \%$ mango and within the Areacaceae (palms), $44 \%$ coconut.

\section{Invasion of rugose whitefly in India}

Initially, this whitefly was observed in several coconut farms in the Pollachi area of Coimbatore district, Tamil Nadu and first reported in Kottayam from kerala during July - August 2016. Based on the puparia of A. rugioperculatus collected by the junior author and by Mr. John Mahesh, Deejay Coconut Nursery Farm in Pollachi (intensive coconut cultivation), Coimbatore, India which were received by the senior author for identification. RSW was described from Belize by Martin on coconut (Cocos nucifera L) by Martin (2004) illustration of the entire puparium was identified 

Aleyrodidae) in India

(Sundararaj and Selvaraj, 2017). RSW was noticed on Coconut palms, mango and guava at Changanassery, Kottayam District, Kerala in India through accidental introduction. A total of 17 plant species under 11 families were recorded as preferred hosts of A. rugioperculatus (Shanas et al., 2016) (Table 1).

Table 1. Host plants of A. rugioperculatus in Kerala

\begin{tabular}{|c|c|c|c|}
\hline S. No. & Common name & Scientific name & Family \\
\hline 1 & Coconut & Cocos nucifera L. & Areaceae \\
\hline 2 & Banana & Musa sp. & Musaceae \\
\hline 3 & Wild jack fruit & *Artocarpus hirsutus Lam. & Moraceae \\
\hline 4 & Jack fruit & Artocarpus heterophyllus Lam. & Moraceae \\
\hline 5 & Brahma's banyan & *Ficus exasperate Vahl., & Moraceae \\
\hline 6 & Mango & Mangifera indica $\mathrm{L}$. & Anacardiaceae \\
\hline 7 & Guava & Psidium guajava $\mathrm{L}$. & Myrtaceae \\
\hline 8 & Brown salwood & *Acacia mangium Willd. & Fabaceae \\
\hline 9 & Malabar tamarind & ${ }^{*}$ Garcinia gummi-gutta $(\mathrm{L})$. & Clusiaceae \\
\hline 10 & Portia tree & Thespesia populnea (L.) & Malvaceae \\
\hline 11 & Wire weed & *Sida acuta Burm. f. & Malvaceae \\
\hline 12 & Indian Almond & Terminalia catappa $\mathrm{L}$. & Combretaceae \\
\hline 13 & Rangoon creeper & ${ }^{*}$ Combretum indicum (L.) & Combretaceae \\
\hline 14 & Golden trumpet & *Allamanda cathartaca $\mathrm{L}$. & Apocynaceae \\
\hline 15 & Oleander & *Nerium oleander $\mathrm{L}$. & Apocynaceae \\
\hline 16 & Garden croton & ${ }^{*}$ Codiaeum verigatum $(\mathrm{L})$. & Euphorbiaceae \\
\hline 17 & Crown of thorns & *Euphorbia milii Des Moul. & Euphorbiaceae \\
\hline
\end{tabular}

* New host records

\section{Damage symptom}

The infestation was found very severe on lower leaves compared to that of the middle and upper young leaves in dwarf and hybrid coconut palms which are about 4 to 6 years old. The population of nymphs ranged between 18 to 37 nymphs $/ \mathrm{cm}^{2}$ of leaflet. RSW excretes a sticky, glistening liquid substance (honeydew), which provides an excellent substrate for growth of sooty molds, which turn the shiny liquid into a black-colored viscous liquid. The layers of sooty mold on leaves may disrupt the photosynthesis process in the host leading to physiological disorders (Stocks and Hodges 2012) (Plate 1).
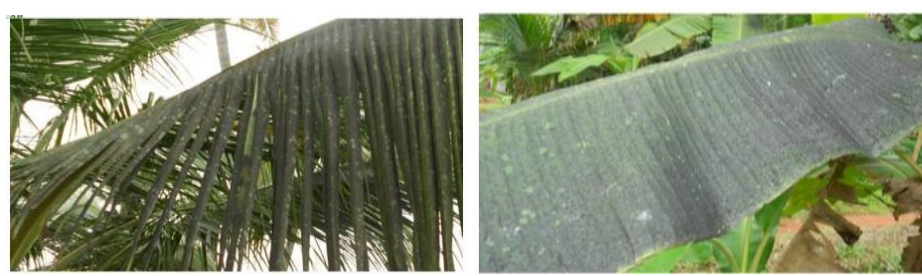

Plate 1. Damage symptom of $A$. rugioperculatus on coconut, banana

\section{Biology}

Eggs: Females lay eggs on the underside of leaves in a concentric circular or spiral pattern and cover it with white waxy matter. Eggs are elliptical and creamy egg on non - plant surfaces such as cars, windows and walls (Plate 2).

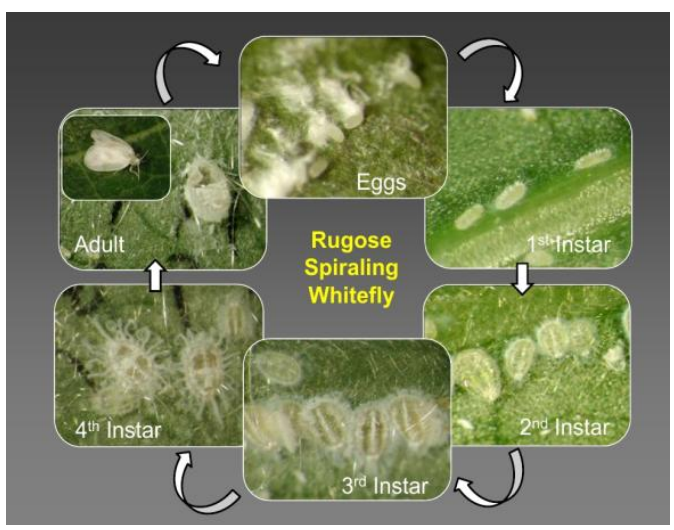

Plate 2. Biology of A. rugioperculatus 


\section{Immature stages:}

Rugose spiraling whitefly has five developmental stages. The first instar, known as the crawler stage (because it is the only mobile immature stage) hatches out of the egg, and looks for a place to begin feeding with its needle - like mouth parts used to suck plant sap. Crawlers molt into immature stages that are immobile, oval and flat initially but become more convex with the progression of its life cycle (Mannion, 2010). Nymphs are about $1.1-1.5 \mathrm{~mm}$ long but many vary in size depending on instars. The nymphs are light to golden yellow in colour, and will produce a dense, cottony wax as well as long, thin waxy filaments which get denser over time (Stocks and Hodges, 2012). The puparium of this species is used for taxonomic identification.

\section{PUPARIUM}

Colonies seen by the author were in generally poor condition, with groups of woolly-wax puparia untidily grouped under the leaves of the host. Margin. Outline oval, 0.97-1.22 mm long, 0.66-0.88 $\mathrm{mm}$ wide, generally widest at abdominal segment III $(\mathrm{n}=35)$. Margin smooth, often down-curved in slide-mounted specimens. Dorsum. Cuticle pale or with variably developed dusky coloration, especially submedially. Longitudinal and transverse moulting sutures reaching puparial margin; transverse moulting sutures apically curving slightly anteriorly, terminating opposite median part of metathorax.

Dorsal disc with subtle reticulate patterning often visible across the cephalothorax (Plate 4) and in abdominal subdorsum, and extremely fine spinulosity present along median line of abdomen. Abdominal segment VII medially reduced to less than half length of segment VI. Vasiform orifice broadly cordate, slightly emarginated to either side of lingula; operculum broadly elliptical except for its anterior edge, ventro-basally spinulose and dorsally characteristically rugose, with a pair of ventromedian fine setae; lingula head protruding beyond vasiform orifice, finely spinulose, apically acute, its four stout setae situated close to apex, which almost reaches puparial margin (Martin, 2004).

Table 2. Distinguishing puparial characters of Rugose spiraling whitefly and spiralling whitefly (Shanas et al., 2016)

\begin{tabular}{|c|l|l|l|}
\hline S. No. & \multicolumn{1}{|c|}{ Puparial character } & A. rugioperculatus & A. dispersus \\
\hline $\mathbf{1}$ & Cuticle on dorsum & Reticulated & Smooth \\
\hline $\mathbf{2}$ & $\begin{array}{l}\text { Compound pores on abdominal segements VII and } \\
\text { VIII }\end{array}$ & Present & Absent \\
\hline $\mathbf{3}$ & Corrugations / rugosity on the surface of operculum & Present & Absent \\
\hline $\mathbf{4}$ & Shape of the apex of lingula & Acute & Oval \\
\hline
\end{tabular}

Adult:

Rugose spiraling whitefly adults are about three times larger (approx. $2.5 \mathrm{~mm}$ ) than the commonly found whiteflies and are lethargic by nature. Although taxonomic identification is required for species confirmation, rugose spiraling whitefly adults can be distinguished by their large size and the presence of a pair of irregular light brown bands across the wings (Stocks and Hodges, 2012). Males have long pincer - like structures at the end of their abdomen (Plate 3).
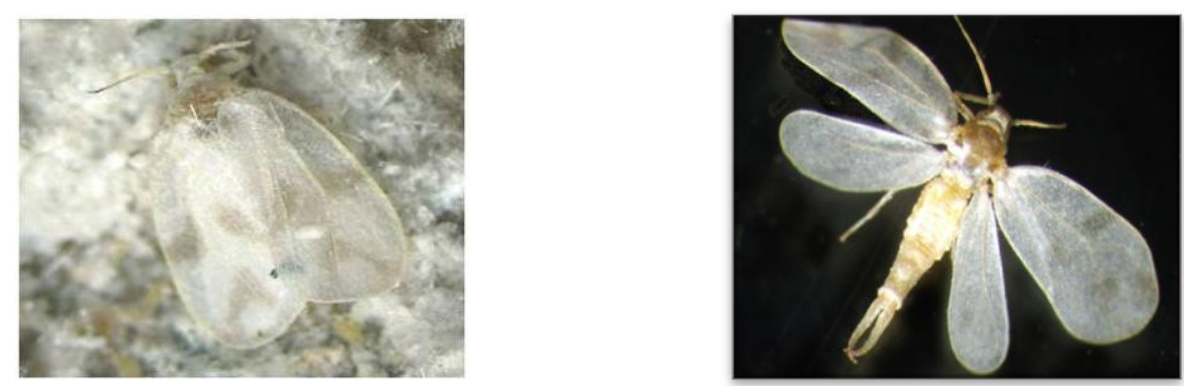

Plate 3. Rugose spiraling whitefly, A. rugioperculatus, a. Male, b. Female 

Aleyrodidae) in India

\section{Management}

Natural enemies to recorded were RSW viz., Encarsia guadeloupae Viggiani, E. noyesi, Alueroctonus vittatus, Nephaspis oculata. Among these E. guadeloupae potential biocontrol agent against RSW as 50 to $60 \%$ natural parasitization.

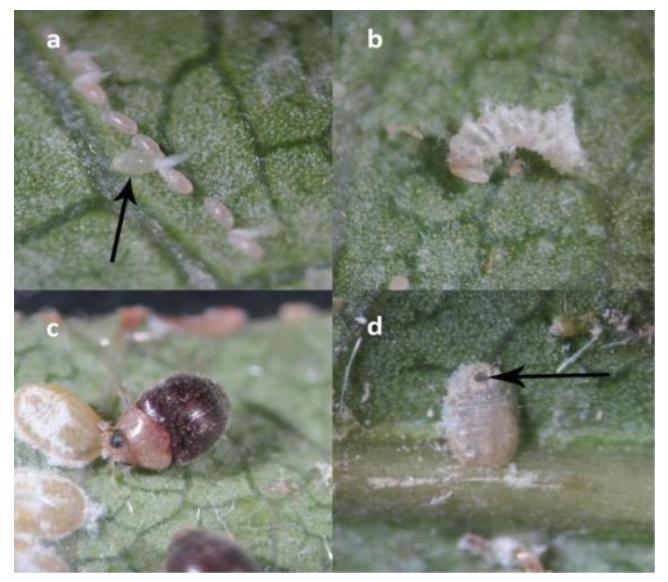

Plate 4. Life stages of Nephaspis oculata. a) A single beetle's egg (arrow) laid adjacent to a row of rugose spiraling whitefly eggs. Rugose spiraling whitefly eggs become darker as they age as can be seen here. The wax on the eggs was removed in order to take this photo. b) Larva feeding on a rugose spiraling whitefly egg. c) An adult male feeding on a 4th instar of rugose spiraling whitefly. d) A hole (arrow) created by the feeding activity of a beetle. The hole looks similar to an exit-hole created by parasitoids (Taravati et al., 2016)
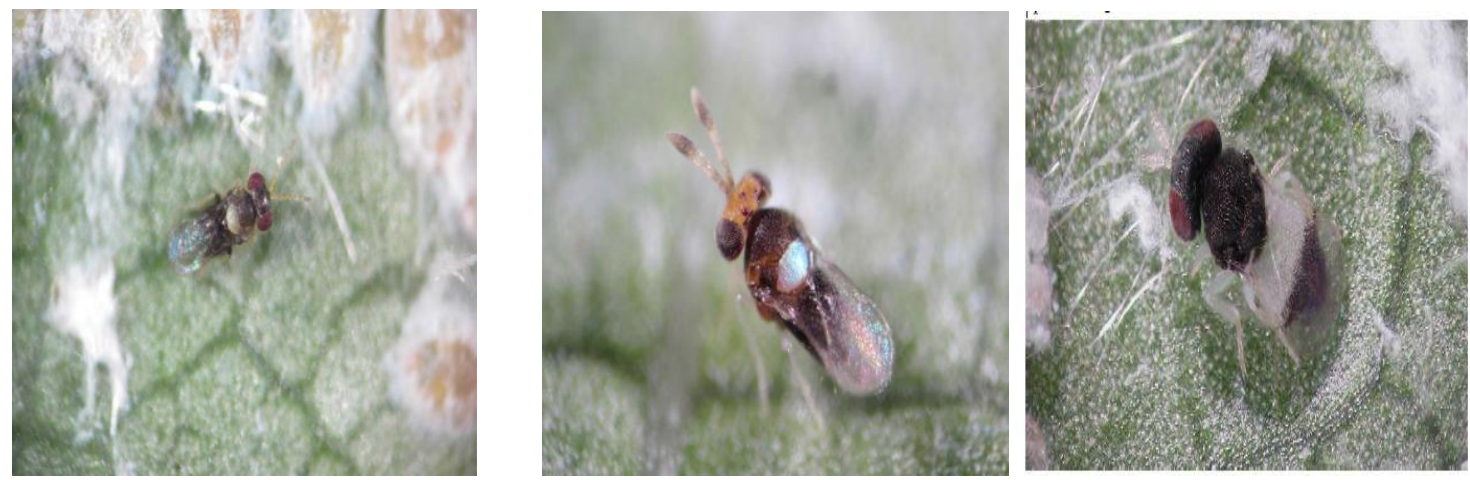

Plate 5. Natural enemies of rugose spiraling whitefly, Encarsia guadeloupae, E. noyesi and Alueroctonus vittatus

\section{Chemical control}

Application of $1 \%$ starch solution on leaflets to flake out the sooty moulds. In severe case, spray neem oil $0.5 \%$. Neonicotionoid insecticides can be applied with foliar, soil or trunk applications. Soil applications include drenching with water using granular formulations on the soil surface, or burying pellets. Trunk application includes basal bark sprays and trunk injection Systemic insecticides are used viz., Acetamiprid, Clothianidin, Dinotefuran and Imidacloprid (Mannion, 2010).

\section{CONCLUSION}

The rugose spiraling whitefly, Aleurodicus rugioperculatus Martin is a polyphagous pest that has caused significant damage in the India. Various plants have been identified as primary hosts in affected areas. Rugose spiraling whitefly was confirmed in 22 counties, and surveys for biological control agents have found several important natural enemies and other species that collectively provide appreciable control of this whitefly pest.

\section{REFERENCES}

Francis, A. W., I. C. Stocks, T. R. Smith, A. J. Boughton, C. M. Mannion and L. S. Osborne. 2016. Host plants and natural enemies of rugose spiraling whitefly (Hemiptera: Aleyrodidae) in Florida. Florida Entomologist, 99(1):150-153 
Mannion, C. 2010. Rugose spiraling whitefly - A new whitefly in South Florida. University of Florida, IFAS Extension Publication (http: // trec. ifas. ufl. Edu / mannion / pdfs / Rugose \% 20 spiraling \% 20 whitefly.pdf) (accessed April 2014)

Martin, J. H. 2004. The whiteflies of Belize (Hemiptera: Aleyrodidae) Part 1-introduction and account of the subfamily Aleurodicinae Quaintance and Baker. Zootaxa, 681: 1-119

Shanas, S., J. Job, T. Joseph and G. Anju Krishnan. 2016. First report of the invasive rugose spiralling whitefly, Aleurodicus rugioperculatus Martin (Hemiptera: Aleyrodidae) from the Old World. Entomon, 41(4): 365 368

Stocks, I.C and G. Hodges. 2012. The rugose spiraling whitefly, Aleurodicus rugioperculatus Martin, a new exotic whitefly in south Florida (Hemiptera: Aleyrodidae). Florida Department of Agriculture and Consumer Services, Division of Plant Industry. http://freshfromflorida. s3. amazonaws.com/ aleurodicusrugioperculatus- pest-alert.pdf (last accessed 15 Mar 2015).

Sundararaj, R. and K. Selvaraj. 2017. Invasion of rugose spiralling whitefly, Aleurodicus rugioperculatus Martin (Hemiptera: Aleyrodidae): a potential threat to coconut in India. Phytoparasitica. DOI 10.1007/s12600-017- 0567-0

Taravati, S., C. Mannion, L. Osborne, and C. McKenzie. 2016. Feeding and development of Nephaspis oculata (Coleoptera: Coccinellidae) on rugose spiraling whitefly (Hemiptera: Aleyrodidae). Florida Entomologist, 99(3): $516-521$

Citation: K. S. Karthick et al., "Newer report of Rugose Spiraling Whitefly, Aleurodicus rugio perculatus Martin (Hemiptera: Aleyrodidae) in India ", International Journal of Research Studies in Zoology, vol. 4, no. 2, p. 12-16, 2018. http://dx.doi.org/10.20431/2454-941X.0402003

Copyright: (C) 2018 Authors. This is an open-access article distributed under the terms of the Creative Commons Attribution License, which permits unrestricted use, distribution, and reproduction in any medium, provided the original author and source are credited. 